\title{
Thin-film PV modules early degradation analysis: a case study on CIGS
}

\author{
A.M. Diez-Suárez ${ }^{1}$, D. de la Calzada-Lorenzo ${ }^{1}$, A. González-Martínez ${ }^{1}$, L. Álvarez-de Prado ${ }^{2}$, \\ Á. de la Puente-Gil ${ }^{1}$, J.J. Blanes-Peiró ${ }^{1}$ and M. de Simón-Martín ${ }^{1}$.
}

\author{
${ }^{1}$ Dep. Area of Electrical Engineering \\ Energy Resources' Smart Management (ERESMA) Research Group \\ School of Mining Engineering, Universidad de León (Spain) \\ Campus de Vegazana s/n, Universidad de León, 24071 - León \\ E-mail: ana.diez.suarez@unileon.es, dcalz100@estudiantes.unileon.es, alberto.gonzalez@unileon.es, \\ laura.alvarez@unileon.es, apueg@unileon.es, jorge.blanes@unileon.es, miguel.simon@unileon.es \\ ${ }^{2}$ Dept. Area of Cartographic, Geodesic and Photogrammetric Engineering \\ Energy Resources' Smart Management (ERESMA) Research Group \\ School of Mining Engineering, Universidad de León (Spain) \\ Campus de Vegazana s/n, Universidad de León, 24071 - León \\ E-mail: laura.alvarez@unileon.es
}

\section{Graphical abstract}

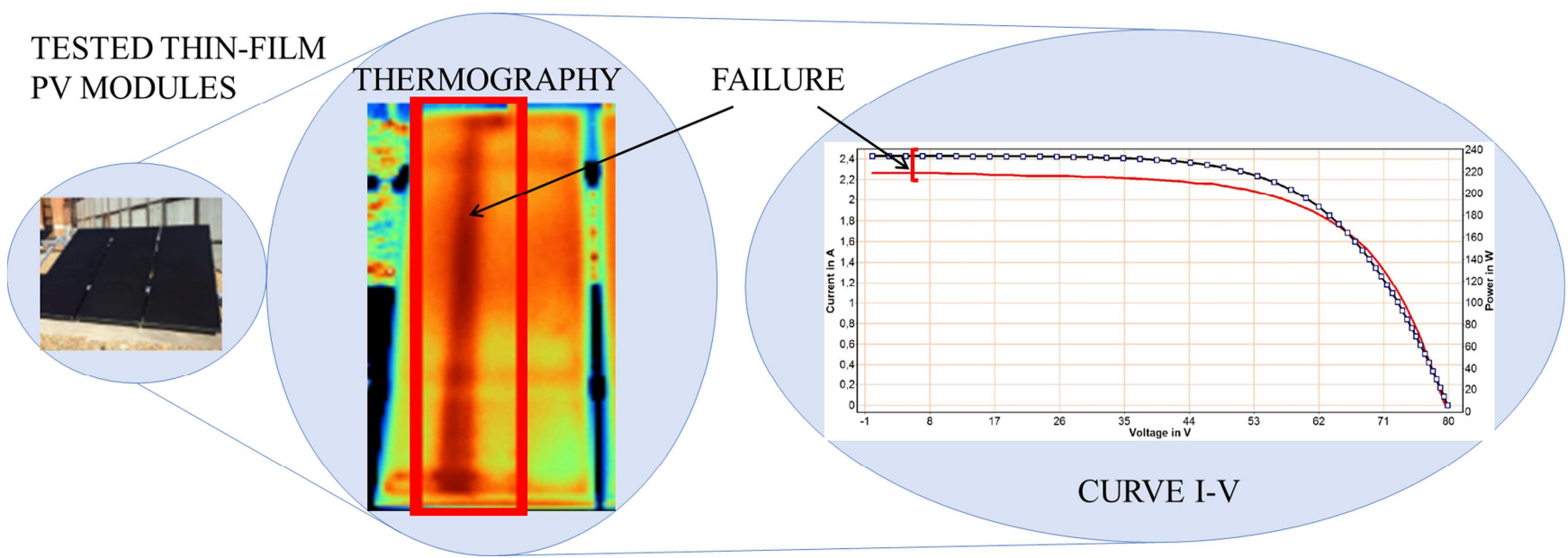

\begin{abstract}
Solar Photovoltaic (PV) energy generation will be one of the main energy generation technologies in the inner future thanks to the recent and significant reduction of involved costs. One of the most promising and lowest cost technologies is the thin-film PV modules technology. Their currently lower performance than single-Si PV modules is compensated by their lower costs and more aesthetical display, which make them especially attractive for building integration. However, because of the novelty of this technology, very few studies have been conducted to analyse its aging and degradation, which has a significant impact on the operation and maintenance needs and, in the end, in its Levelized Cost of Energy (LCOE). Thus, in this work, a systematic review on this technology and on its more
\end{abstract}

frequent faults and degradation effects is conducted first. Then, a set of Copper Indium Gallium Selenide (CIGS) PV modules has been tested under real outdoor conditions and its degradation has been analysed after 3 years operation. A new procedure for faults location and quantification has been established for this sort of PV modules; and early degradation and aging data are presented and analysed. Results show a significant early degradation of this technology and a fast expansion of the PV faults.

\section{Key words}

Thin film PV, PV degradation and aging, PV faults, CIGS. 


\section{Introduction}

The promotion of renewable energy sources (RES), especially for electricity generation, results unstoppable and mandatory in a near future. Several countries all around the world, particularly in Europe, have adopted the commitment to eliminate not renewable energy sources from their energy systems for 2050 in order to decarbonize their economies.

Global energy demand grew $2.1 \%$ in 2017 , which means that the growth rate in 2016 has been doubled. Global energy demand in 2017 reached an estimated 14,050 million toe (tons of oil equivalent). On the other hand, renewable energy sources recorded the highest growth rate from all energy sources in 2017, being a quarter of the global rate of growth in energy demand. Moreover, electricity generation from renewable energy sources increased by $6.3 \%$ (i.e. $380 \mathrm{TWh}$ ) in 2017 , representing $25 \%$ of the world's electricity generation [1].

According to the scenario presented, solar energy systems undoubtedly will constitute a key for future development and many international effort are being conducted to improve the efficiency, compactness and feasibility of these technologies, as well as reducing both capital and operation and maintenance costs [2]. In fact, if the Levelized Cost of Energy (LCOE) -which evaluates the overall cost of the generated energy considering both capital costs, O\&M (operation and maintenance) costs and degradation- is considered, the solar photovoltaic generation is currently one of the best options in comparison with other RES and, in many cases, is achieving even grid parity [3].

There are several recent developments in the PV field. One of the most promising technologies for Building Integrated PV systems (BIPVs) are the so-called "thin-film $P V$ modules", due to their low capital costs and aesthetic options. Within the different PV solar energy technologies, thin-film PV modules are an interesting option. Both characteristics make this technology attractive for buildings and other urban structures integration. Because of their promising aptitudes to be integrated in a massive way in building façades, precise degradation studies and preventive maintenance programs must be developed.

Currently, four types of PV modules are the most widespread in the market [4]:

1) Monocrystalline silicon PV modules: The electricity is generated by a set of silicon PV cells that have been extracted from a single crystal of doped silicon. They show the highest market efficiencies but also high manufacturing costs.

2) Polycrystalline silicon PV modules: In this case, the set of silicon PV cells are extracted from a piece of doped silicon with several crystal formations. They show a significant lower manufacturing cost, but its market efficiency is also lower.

3) Amorphous silicon PV modules: The PV cells in the cell array of this sort of modules are manufactured with doped silicon without crystallization. This means the lowest costs, but also the lowest efficiency.

4) Thin-film PV modules: They are created by a huge PV cell that occupies the whole module. This cell can be made of single, poly or even amorphous silicon by deposition on a support material, being its efficiency and costs related accordingly. It is one of the latest solar technologies commercially available.

There exist other promising technologies, such as perovskites-based PV cells, organic PV cells or rare earth elements-based PV cells (e.g. CdTe or InGa) but they are not representative in the photovoltaic market now.

An essential feature of the thin-film PV modules is their minimum material usage and rising efficiencies. This advantage allows these modules to be more flexible and adapted to different geometries base surfaces. Moreover, its manufacture process is cheaper than other technologies, such as monocrystalline silicon modules, since less material thickness is necessary. On the other hand, they seem to be more sensitive to partial shadows and high temperatures, affecting significantly its performance.

Thin-film PV modules can be classified according to the photo-electric sensitive material into 3 main groups [5]:

1) Amorphous silicon $(\alpha-S i)$.

2) Copper indium gallium selenide (CIGS).

3) Cadmium telluride (CdTe).

In this research work, it is intended to provide a deep description of the main failures that this technology may suffer from, and that may affect their degradation and aging. Then a case study is presented showing the results on five CIGS thin-film PV modules tested and monitored along three years of operation under real conditions.

\section{Main failures in thin-film PV modules}

Due to the relative novelty of this technology (in comparison with traditional silicon PV modules), very few results have been obtained concerning this technology aging, degradation and frequent failures. The main guidelines in this field are provided for cells array PV modules. In addition, the existing variety of thin-film $\mathrm{PV}$ modules is wider than in other Si PV crystalline modules. Therefore, it has been observed that many failures have been reported only for very specific manufacturers.

As commonly found PV faults in thin-film PV modules outstand delamination, glass breakage or junction box failures. For $\alpha-S i$ based PV modules, Induced Light Degradation (LID), annealing instabilities and hot spots have been reported. On the other hand, in the case of CdTe PV modules, cell layer integrity problems, back sheet contact stabilities, busbar failures, mechanical (adhesion) problems and electrical hot spots seem to be 
the most frequent failures. Finally, regarding CIGS PV modules, hot spots are characterized as a typical fault [6].

From the above-mentioned faults, the most widespread and dangerous ones are:

1) Delamination: Thin-film PV modules may contain a transparent conductive oxide (TCO) layer that can delaminate from an adjacent glass layer [7]. In general, the delamination process starts in a contamination in the manufacturing process, poor cleaning or environmental factors, which will also cause the entry of moisture and corrosion.

2) Back sheet adhesion loss: Specifically, this failure presents an important safety hazard in addition to significant power losses. Small air gaps can be produced along cracks in the back sheet and a high voltage can appear between both parts, capable of producing, and sustaining, an electric arc.

3) Hot spots: Two types of hot spots must be differentiated according to their origin: those from the manufacturing process (usually as result of the evolution of a crack), and those originated by a reverse bias operation due to partial shading. The latest are the most often in the case of thinfilm PV modules, which are extremely sensitive to reverse bias operation. It must be noticed that hot spots usually lead to point-local heating (hotspot heating), that can cause severe damage.

\section{Case study and inspection methodology}

As case study, five CIGS PV modules have been supervised and monitored working under real outdoor conditions in a testing lab facility. These modules have been installed in an open rack in a horizontal roof of the School of Mining Engineering at the Universidad de León (Spain). The five modules are connected in a series string of a $1.5 \mathrm{~kW}$ single-phase power inverter and they have been working in parallel with monocrystalline $\mathrm{Si} \mathrm{PV}$ modules, used in this case as power production reference. Moreover, weather conditions have been also monitored through a weather station according to the WMO (World Meteorological Organization) standards. The living test facility is part of a Smart Grid living test-bed which also accounts with a $11.6 \mathrm{~kW}$ peak power PV system and a $9.6 \mathrm{kWh}$ rated capacity of ion-lithium energy storage system.

The PV modules have been supervised during 3 years of outdoor operation and they have been subject to several periodical tests and inspections with the aim to report potential failures and aging degradation.

The five CIGS thin-film PV modules were manufactured by TSM, and they belong to TS-140C2-T range. Their rated power is $140 \mathrm{~W}$ peak power $(140 \mathrm{Wp})$ each, and they are installed on the same rack and connected to a SMA Sunny Boy 1300TL single-phase inverter.
The inspection methodology is based in four main steps, according to previous works and that are detailed in the following paragraphs [8]:
A. Visual inspection.
B. Thermographic inspection.
C. Measurement of electrical parameters (I-V test).
D. Data storage and analysis through a Geographic Information System (GIS) tool.

\section{A. Visual Inspection}

The visual inspection must be the first action when evaluating a PV field condition. Many faults and damages can be found directly by this process, but it should be carried out carefully.

However, some faults can be imperceptible to the naked eye, such as micro-cracks, so, the visual inspection should be supported by image processing techniques. Nevertheless, the visual inspection can result very effective for the identification of hot spots, delamination problems, cracks formation, air bubbles apparition on the back sheet and potential failures in the junction box, among others.

The visual inspection of thin-film modules should be conducted in a systematic way, and then, standardized tests such as those described in the IEC 61646 standard [9] are advised.

Before conducting a visual inspection, it should be considered:

- Thorough cleaning of the PV modules to remove any possible dust that may exist on their surface. The cleaning-up operation must be done with a lint-free cloth, moistened in water without adding any additive.

- The visual inspection must be carried out under good atmospheric conditions, which means, clear sky conditions and a solar global irradiance higher than $700 \mathrm{~W} / \mathrm{m}^{2}$.

If a failure appears under the visual inspection it must be reported systematically. Thus, it is advised to register them in a module scheme, such as shown in Fig. 1. In the case study, PV modules measure 1,656 x $656 \mathrm{~mm}$. As thin-film modules do not have separated visual parts, in this case, the external surface of the PV modules have been divided into 160 equal parts whose dimensions are $76.88 \times 80.15 \mathrm{~mm}$. Each cell of the array is then identified by a letter (row) and a number (column), as it can be seen in Fig. 1 . 


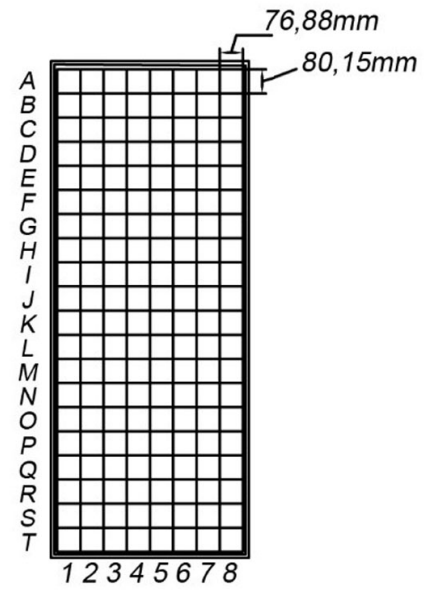

Fig. 1. PV module scheme for failures reporting.

\section{B. Thermographic inspection}

Many faults can be easily detected through the thermal footprint. Thus, a thermographic inspection must be considered if possible. Although other actual technologies, such as electroluminescence inspections can offer better results, their costs are still not affordable for small facilities. However, the costs of thermographic cameras have drop significantly in the recent times and now it is a costless and effective inspection technique for electrical facilities.

In this case, for the thermal analysis of the PV modules under study, a Fluke Ti40 thermal camera was used. The camera captures a radiometric thermal picture along with a visible light image superimposing them pixel by pixel. The camera detects the electromagnetic radiation emitted by the PV module and it is then converted into an electrical signal thanks to a two-dimensional array of sensors, then it is amplified and, finally, it is converted to digital format, being able to visualize it on the camera's TFT screen or in a PC.

When conducting the thermographic inspection, it is mandatory to guarantee that there are no shadows projected on the PV modules during the process. This could cause unexpected irregular thermal areas, and then, a misinterpretation of the results. Moreover, high wind speed conditions must be avoided as convection thermal exchange may diffuse the thermal picture.

The most favourable conditions to take good quality and representative thermal pictures occur when the PV module is working at its maximum power conditions, which usually takes place with clear sky conditions at noon [10]. Thus, thermograph pictures should be taken with a minimum $700 \mathrm{~W} / \mathrm{m}^{2}$ of solar global and in a 3- or 4-hours' time interval at noon.

Moreover, in order to minimize interferences caused by reflections from the front part of the PV module, frontal and rear thermograph pictures are advised to be taken. Special care on the corrections are needed for rear thermographs as the temperature might be higher due to poor thermal dissipation [11]. Figs. 2 and 3 show both examples of frontal and rear thermograph pictures taken in the test-bed facility.

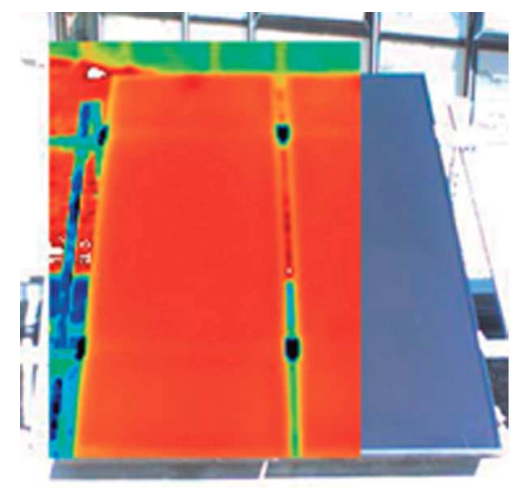

Fig. 2. Frontal thermograph picture of a CIGS PV module.

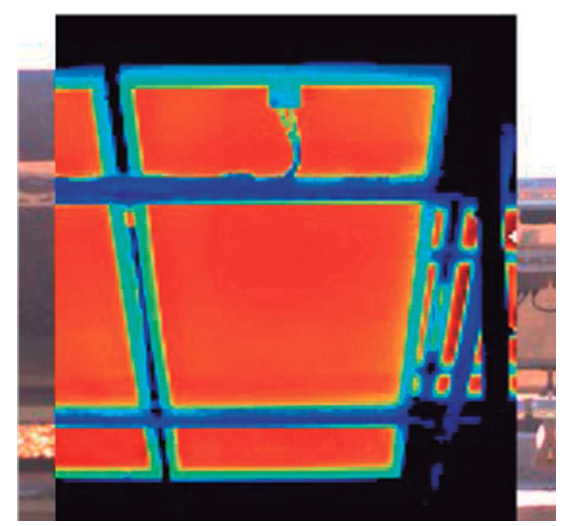

Fig. 3. Rear thermograph picture of a CIGS PV module.

Rear thermograph pictures avoid problems related to solar reflections or those derived from the low emissivity associated with the crystalline surface of the module. When using the camera, a good approach is essential to provide an optimum resolution of the recognized area.

Hot spots in thin-film PV modules can be easily detected by thermography.

\section{Measurement of electrical parameters}

The electrical parameters (voltage, current, fill factor, internal series and parallel resistances and output power) measurement and analysis will quantify the degradation suffered by the PV modules.

By means of the I-V curves, the PV modules performance can be compared with the un-boxing conditions. In the case that the flash-test report of the PV module (which is unique for each module and shows its real performance before being installed), the I-V curve from the technical sheet can be used as reference.

In this case, a PVPM 1000CX I-V tracer has been used. In order to measure the I-V curve stable light temperature conditions must be provided. The I-V curve can be also measured for a complete series. In this case, the maximum voltage supported by the PVPM 1000CX I-V tracer is $1,000 \mathrm{~V}$ and the maximum current is $20 \mathrm{~A} \mathrm{[12].}$ 
At the same time, the global irradiance on the PV module is measured by a calibrated photoelectric cell (sensor PHOX SOZ-03), as well as the PV temperature with a temperature probe (RTD Pt100) in order to extrapolate the measured conditions to the standard conditions (STC).

Power losses due to the accumulation of superficial dirt can reach between $1.5 \%$ and $6.2 \%$. Then, it is important to clean the module's surface before the I-V curve measurement to obtain reliable results [13].

The measurement results are usually exported to a computer through a specific software that allows further analysis. Fig. 4 shows an example of an I-V curve corresponding to one of the tested CIGS PV modules.

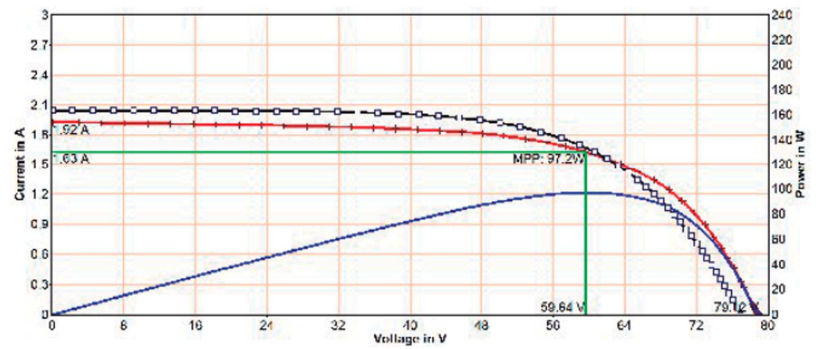

Fig. 4. I-V curve of a CIGS PV module.

\section{Data storage and analysis through a GIS-based tool}

The previous inspection steps generate a lot of information and files: pictures, thermographic pictures, I-V curve reports, electrical parameters datasheets, weather conditions datasheets, etc. Moreover, if several inspections are carried out along time, the information size growths exponentially. Then, a systematic method to gather all the information and its comparative analysis is needed. Currently, GIS tools have developed outstanding characteristics that make them appropriate for this work. They allow the management of lots of data, spatially referenced and a visualization through interactive maps [14].

For this study, a novel GIS tool was developed to collect and compile a dataset of several PV variable values. Fig. 5 shows a screenshot of the developed GIS-based tool where the thin-film PV modules can be identified and the measured (STC) short circuit current values is shown.

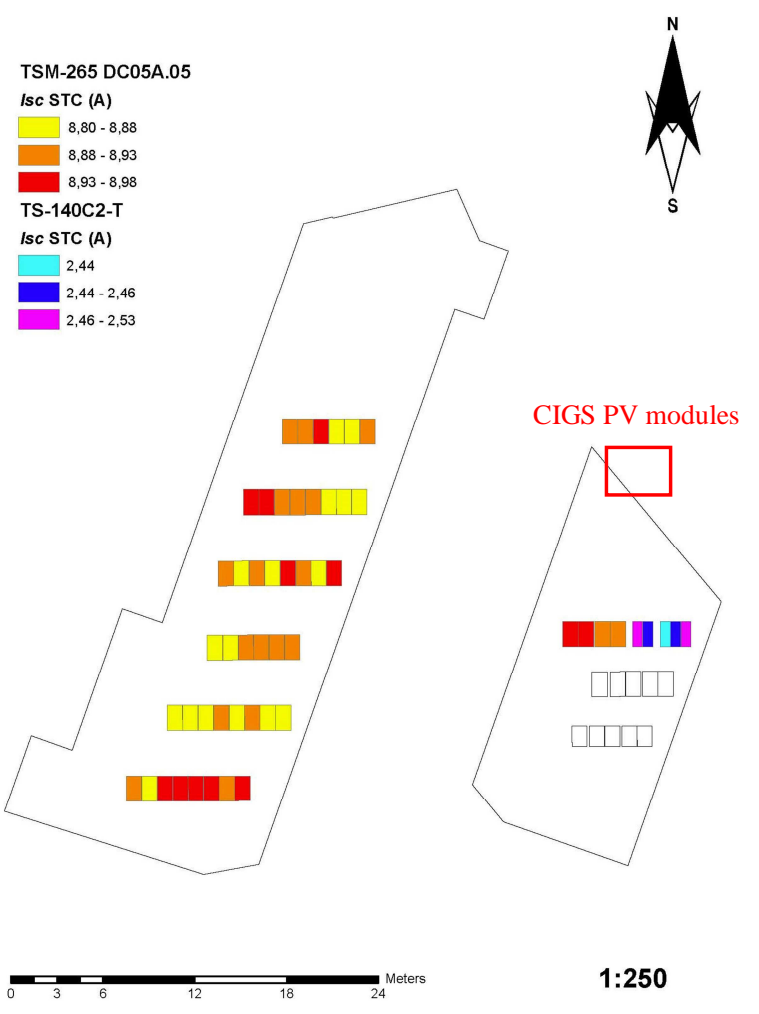

Fig. 5. Screenshot of the GIS-based monitoring tool.

The recorded data include both defects or failures detected through the visual inspection, the thermographic pictures and the I-V measurements. Then, a base map and an associated database were created, as well as the procedures to systemize the data collection and analysis. Thus, the correlation of the PV defects existence, not only with the power losses on the affected PV module, but also to the overall performance of the PV power plant, can be done in a fast and easy way.

\section{Results analysis}

Both a failures analysis and degradation study have been conducted. The degradation analysis has been performed by applying the inspection procedure detailed in the previous section, while the degradation analysis has been carried out by comparing the flash-test measurements with the latest ones, always referred to STC conditions.

A flash-test is a standard procedure conducted by the manufacturers to guarantee that a manufactured PV module fulfils the quality standards. It is usually conducted in a test room where the PV module is undergone to a flash light, with the sunlight spectre, during a few seconds and the I-V curve is measured. The STC test conditions is an industry-wide standard to compare the PV modules performance and specifies a cell temperature of $25^{\circ} \mathrm{C}$ and an incident global irradiance of $1,000 \mathrm{~W} / \mathrm{m}^{2}$ with an air mass of 1.5 (AM1.5) spectrum. These conditions correspond to the irradiance and sunlight spectrum of a clear day upon a 
sun-facing $37^{\circ}$-tilted surface with a sun's elevation angle of $41.81^{\circ}$ above the horizon.

Thanks to the GIS-based application, the spatial distribution of the PV faults can be seen, allowing an evaluation the impact of the damaged PV modules mismatching with unharmed ones.

In the visual inspection, only one defect was detected in the CIGS thin-film PV modules (module ID: 03), as it can be seen in Fig. 6. It is a hot spot spread as a whole stripe from the bottom to the top parts of the PV module, which is called hot spot stripe. This sort of fault have been previously reported in other works which detected it in laboratory tests by using electroluminescence and lock-in thermography techniques [15].

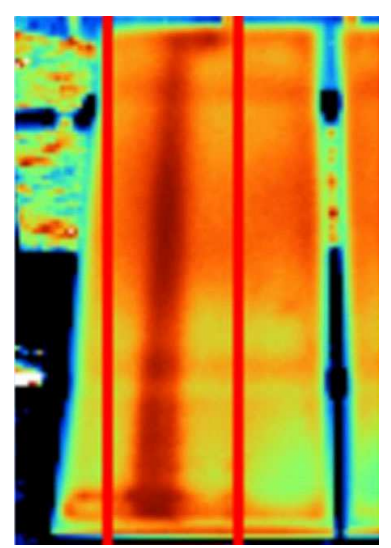

Fig. 6. Thermographic picture of the found hot spot stripe on CIGS thin-film module ID 03.

Table I. Electrical parameters of each of the five modules, the flash test and the measurement made

\begin{tabular}{|c|c|c|c|c|c|c|c|c|c|c|}
\hline Module & & $I_{S C}(\mathrm{~A})$ & $V_{O C}(\mathrm{~V})$ & $I_{M P P}(\mathrm{~A})$ & $V_{M P P}(\mathrm{~V})$ & $P_{M P P}(\mathrm{~W})$ & $F F(\%)$ & $R_{S}(\Omega)$ & $R_{P}(\Omega)$ & Failures \\
\hline \multirow{3}{*}{1} & Flash test & 2.71 & 85.05 & 2.38 & 59.80 & 142.6 & 61.75 & 9.42 & 1208 & \multirow{3}{*}{0} \\
\hline & Measured (STC) & 2.50 & 83.40 & 2.25 & 64.00 & 144.2 & 69.06 & 4.44 & 1793 & \\
\hline & Deviation & -0.21 & -1.65 & -0.13 & 4.20 & 1.63 & 7.32 & -4.98 & 585 & \\
\hline \multirow{3}{*}{2} & Flash test & 2.73 & 85.93 & 2.39 & 60.49 & 144.5 & 61.63 & 9.70 & 1172 & \multirow{3}{*}{0} \\
\hline & Measured (STC) & 2.45 & 89.20 & 2.08 & 66.80 & 139.0 & 63.58 & 11.77 & 1014 & \\
\hline & Deviation & -0.28 & 3.27 & -0.31 & 6.31 & -5.53 & 1.95 & 2.07 & -158 & \\
\hline \multirow{3}{*}{3} & Flash test & 2.66 & 86.48 & 2.26 & 63.30 & 143.3 & 62.19 & 11.69 & 904 & \multirow{3}{*}{1} \\
\hline & Measured (STC) & 2.44 & 87.90 & 2.07 & 66.80 & 138.6 & 64.47 & 10.74 & 1004 & \\
\hline & Deviation & -0.22 & 1.42 & -0.19 & 3.50 & -4.69 & 2.28 & -0.95 & 100 & \\
\hline \multirow{3}{*}{4} & Flash test & 2.69 & 85.60 & 2.36 & 61.18 & 144.6 & 62.70 & 9.03 & 1221 & \multirow{3}{*}{0} \\
\hline & Measured (STC) & 2.46 & 84.30 & 2.20 & 64.50 & 141.9 & 68.43 & 5.03 & 1701 & \\
\hline & Deviation & -0.23 & -1.30 & -0.16 & 3.32 & -2.72 & 5.72 & -4.00 & 480 & \\
\hline \multirow{3}{*}{5} & Flash test & 2.72 & 81.77 & 2.43 & 58.69 & 142.6 & 64.12 & 6.98 & 1416 & \multirow{3}{*}{0} \\
\hline & Measured (STC) & 2.53 & 82.90 & 2.28 & 64.90 & 147.7 & 70.55 & 3.68 & 1815 & \\
\hline & Deviation & -0.19 & 1.13 & -0.15 & 6.21 & 5.13 & 6.43 & -3.30 & 399 & \\
\hline
\end{tabular}

Finally, Table I summarizes the main electrical parameters evolution on the five tested CIGS thin-film PV modules. The failure detected in module ID03 is a hot spot stripe. Although, hot spots in thin-film PV modules are usually caused by partial shading conditions, this is not the case as no shadows are projected on the PV modules. On the other hand, a manufacturing origin is also discarded, as it was not registered before installation. Therefore, it could be possible an spontaneous origin reason, as other authors have reported -hot spots with significant temperature increase $(\sim 300 \mathrm{~K})$ can spontaneously emerge in laterally uniform thin film photovoltaics- [16]. However, as shown in Table I, the hot spot stripe seems not to have a significant impact on the module's performance.

By comparing the peak power values from the flash-test reports with the after-operation measurement, it is observed a performance decrement. It is clearly reported in modules 2, 3 and 4, which could achieve the $1.27 \%$ /year, which is significantly higher than typical degradation rates for crystalline $\mathrm{Si}$ of $0.5 \%$ year. It also should be noticed that the short circuit current $\left(I_{S C}\right)$ and maximum power point current $\left(I_{M P P}\right)$ values have worsened in all CIGS modules.

The $3.3 \%$ reduction of the peak power on the hot spot stripe affected module can be caused by the substantial increase of the cell temperature that the failure has provoked. Further studies must be conducted in this way.

Finally, it is also significant the differences in the series and parallel internal resistances. In all cases, but module ID02, their values have improved (series resistance is lower and parallel resistance is higher). This may be due to its estimation is conducted by classical approaches valid for crystalline Si PV modules, but may differ on thin-film PV modules. 


\section{Conclusions}

The degradation study and analysis of CIGS PV modules results fundamental to estimate real performance of BIPVs among their lifespan. This study is just the starting point to collect data of the real performance of this sort of PV modules during their useful lifespan, which complement the estimations of induced stress tests from laboratories.

Nowadays, photovoltaic manufacturers demand advanced maintenance techniques based on the recognition of degradation patterns in order to lengthen the useful life of the facilities, and therefore reduce their LCOE.

In this paper, a systematic inspection procedure specially designed for thin-film modules is provided, as well as a concise review of the main failures and faults of this technology. Moreover, an incipient degradation study is provided with a sample of five CIGS thin-film PV modules and above normal degradation rates have been observed.

Furthermore, one hot spot stripe has been detected in a PV module working outdoors only for 3 years, which origin seems to be spontaneous. Although most electric parameters seem to be in the normal range in this module, a significant $3.3 \%$ peak power dismiss has been observed.

\section{Acknowledgement}

This paper has been published thanks to the support of the Laboratorio de Inspección Técnica de la Escuela de Minas (LITEM), Universidad de León (Spain). The authors want to thank all contributors to the project, especially to Carlos Martínez Fernández, and to the Conference Chair and reviewers for their valuable comments to increase the overall quality of the manuscript.

\section{References}

[1] IEA International Energy Agency, «Global Energy \& CO2 Status Report The latest trends in energy and emissions in 2017», IEA International Energy Agency, mar. 2018.

[2] M. Malinowski, J. I. Leon, y H. Abu-Rub, «Solar Photovoltaic and Thermal Energy Systems: Current Technology and Future Trends», Proc. IEEE, vol. 105, n. ${ }^{\circ}$ 11, pp. 2132-2146, nov. 2017.
[3] F. Ueckerdt, L. Hirth, G. Luderer, y O. Edenhofer, «System LCOE: What are the costs of variable renewables?», Energy, vol. 63, pp. 61-75, 2013.

[4] K. P. Bhandari, J. M. Collier, R. J. Ellingson, y D. S. Apul, «Energy payback time (EPBT) and energy return on energy invested (EROI) of solar photovoltaic systems: A systematic review and meta-analysis», Renew. Sustain. Energy Rev., vol. 47, pp. 133-141, 2015.

[5] T. D. Lee y A. U. Ebong, «A review of thin film solar cell technologies and challenges», Renew. Sustain. Energy Rev., vol. 70, pp. 1286-1297, 2017.

[6] Köntges M. et al., «IEA-PVPS T13-01 2014 Review of Failures of Photovoltaic Modules Final», IEA International Energy Agency, mar. 2014.

[7] K. W. Jansen y A. E. Delahoy, «A laboratory technique for the evaluation of electrochemical transparent conductive oxide delamination from glass substrates», Thin Solid Films, vol. 423, n. ${ }^{\circ}$ 2, pp. 153-160, 2003.

[8] M. de Simón-Martín, A. M. Diez-Suárez, L. Álvarez de Prado, A. González-Martínez, Á. de la Puente Gil, y J. Blanes-Peiró, «Development of a GIS tool for high precision PV degradation monitoring and supervision: Feasibility analysis in large and small PV plants», Sustain. Switz., vol. 9, n. ${ }^{\circ}$ 6, 2017.

[9] AENOR, Norma UNE-EN 61646:2009 Módulos fotovoltaicos $(F V)$ de lámina delgada para uso terrestre. Cualificación del diseño y homologación. p. 50.

[10] J. A. Tsanakas, L. Ha, y C. Buerhop, «Faults and infrared thermographic diagnosis in operating $\mathrm{c}-\mathrm{Si}$ photovoltaic modules: A review of research and future challenges», Renew. Sustain. Energy Rev., vol. 62, pp. 695-709, sep. 2016.

[11] FLIR, «Thermal imaging guidebook for building and renewable energy applications», Infrared Training Center (ITC), Wilsonville. Oregón, Informative guide, 2011.

[12] «Peak Power Measuring Device and I-V Curve Tracer for PV Moduls and Generators. User Manual», PVEngineering GmbH, Iserlhon. Germany, User Manual, nov. 2013.

[13] M. R. Maghami, H. Hizam, C. Gomes, M. A. Radzi, M. I. Rezadad, y S. Hajighorbani, «Power loss due to soiling on solar panel: A review», Renew. Sustain. Energy Rev., vol. 59, pp. 1307-1316, jun. 2016

[14] F. J. M. Teo, Tecnología de los Sistemas de información Geográfica. Ra-ma, 1995.

[15] A. Gerber et al., «Advanced large area characterization of thin-film solar modules by electroluminescence and thermography imaging techniques», Sol. Energy Mater. Sol. Cells, vol. 135, pp. 35-42, abr. 2015.

[16] A. C. Vasko, A. Vijh, y V. G. Karpov, «Hot spots spontaneously emerging in thin film photovoltaics», ArXiv14010056 Cond-Mat, dic. 2013. 